\title{
Results from the Bailiwick of Guernsey's 2018 Report Card on Physical Activity for Children and Youth
}

\author{
Alun Williams, Lucy Whitman, Yve Le Page, Colin Le Page, Graham Chester, and Simon J. Sebire
}

\section{Introduction}

This is the first Report Card undertaken in the Bailiwick of Guernsey (Referred to as Guernsey in this document). Located in the English Channel and near the French coast, Guernsey is a self-governing British Crown Dependency with a population of approximately 63,000 . Similar to England, ${ }^{1}$ previous local schoolbased surveys suggest that few of Guernsey's children and youth meet recommendations for 60 minutes of moderate-to-vigorous intensity physical activity per day. Such levels of inactivity undermine the development, health, and well-being of current children and youth as well as future generations. This Report Card will summarise the existing evidence on levels and provision of physical activity amongst Guernsey's children and youth (Figure 1).

\section{Methods}

Using available evidence, five indicators have been reported on Overall Physical Activity, Organized Sport Participation, Active Transportation, Sedentary Behaviors, Government. The remaining indicators of physical fitness, family and peers, school, community and environment were all graded as inconclusive. The main data source was the most recent Guernsey Young People's Survey, undertaken in spring/ summer 2016. The online survey was administered in 16 primary (100\% of all schools) and 8 secondary and post-16 schools (75\% of all schools). In primary schools, 591 Year 6 pupils (95\% of eligible pupils) participated and in secondary schools 985 pupils from Years 8 and 10 (80\% of eligible pupils) participated. Survey questions used in this report card were selfreported: number of days on which they performed moderate-to vigorous physical activity for $\geq 60 \mathrm{mins}$, attendance at a sports club in the 4 weeks before the survey, travel mode to school on the day of the survey and screen time on the previous day. The grades were assigned by the Guernsey Report Card Research Working Group representing a cross-sector panel comprising government departments, third sector organisations, and academics with diverse expertise in the activity levels of young people in Guernsey (listed above as authors). Benchmarks were applied according to the criteria established by the Global Matrix 3.0.

\section{Results and Discussion}

Data indicates that Guernsey is similar to other Very High HDI countries in recording a small proportion of Guernsey children and youth accumulating the recommended amount of moderate-tovigorous intensity physical activity on a daily basis. Equally, the levels of sedentary behavior are of concern especially amongst the older cohort. Few young Guernsey people undertake active transportation to and from school.

The grades and rationale for the report card are included in Table 1 below.

Whilst the survey data source provided a high level of coverage of the target year groups, gaps in the local evidence base prevented the grading of five indicators. Broader and more robust monitoring (including school policy/provision measures and objective assessment of physical activity levels) would provide further insight into the physical activity levels of Guernsey's children and young people.

\section{Conclusion}

Guernsey's youth are not immune to global trends towards low levels of physical activity and active transportation and high levels of sedentary behavior. Yet, islands like Guernsey have a golden opportunity to develop a coordinated and collaborative community response to increasing physical activity in children and youth. There has been recent promising evidence of government commitment to support such a response and to ensure this remains a priority. Making child and youth physical activity "everyone's business" will be key to its success.

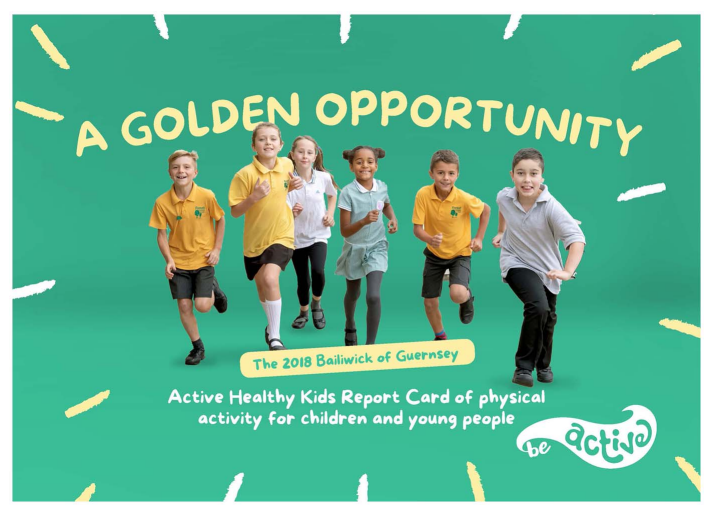

Figure 1 - Guernsey's 2018 Report Card cover.

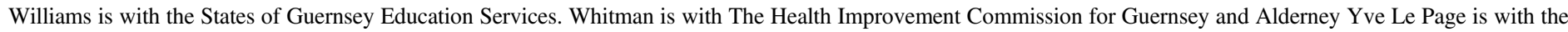

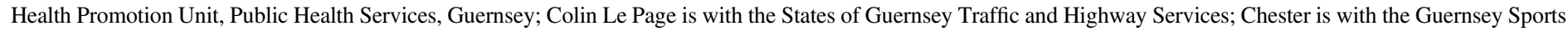

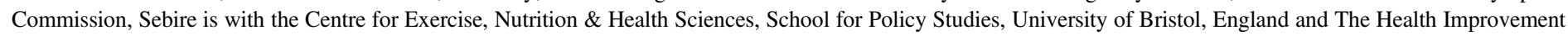
Commission for Guernsey and Alderney. Williams (alun.williams@gov.gg) is corresponding author. 
Table 1 Grades and rationales for Guernsey's 2018 Report Card

\begin{tabular}{|c|c|c|}
\hline Indicator & Grade & Rationale \\
\hline $\begin{array}{l}\text { Overall Physical } \\
\text { Activity }\end{array}$ & $\mathrm{D}$ & $\begin{array}{l}27 \% \text { of primary school pupils and } 22 \% \text { of secondary pupils did physical activity that caused them to breathe faster } \\
\text { and feel warmer for an hour or more on at least } 4 \text { days in the week before the survey. }\end{array}$ \\
\hline $\begin{array}{l}\text { Organized Sport } \\
\text { Participation }\end{array}$ & $\mathrm{C}+$ & $\begin{array}{l}66 \% \text { of primary school pupils and } 52 \% \text { of secondary school pupils reported attending a sports club (not school club } \\
\& \text { not just watching) in the } 4 \text { weeks before the survey. }\end{array}$ \\
\hline Active Play & Inc & Data are not currently collected on active play \\
\hline Active Transportation & $\mathrm{D}$ & $\begin{array}{l}43 \% \text { of primary pupils and } 25 \% \text { of secondary school pupils reported active travel to school on the day of the survey } \\
\text { (walking/ bicycle/ scooter). Years } 6,8+10 \text { average }=31 \%\end{array}$ \\
\hline Sedentary Behaviors & $\mathrm{C}$ & $\begin{array}{l}74 \% \text { of primary school pupils and } 39 \% \text { of secondary school pupils reported no more than } 2 \text { hours of screen time on } \\
\text { the day before survey. Years } 6,8+10 \text { average }=57 \% \text {. }\end{array}$ \\
\hline Physical Fitness & Inc & Sufficient data are not currently collected on physical fitness \\
\hline Family and Peers & Inc & Data are not currently collected on family and peer influence on physical activity \\
\hline School & Inc & $\begin{array}{l}\text { Whilst there is lots of good practice in this area in schools, formal data are not collected at present. Our intention is to } \\
\text { formalise this in time for the } 2020 \text { Global Matrix }\end{array}$ \\
\hline $\begin{array}{l}\text { Community and } \\
\text { Environment }\end{array}$ & Inc & Data are not currently collected on community and the built environment \\
\hline Government & $\mathrm{D}$ & 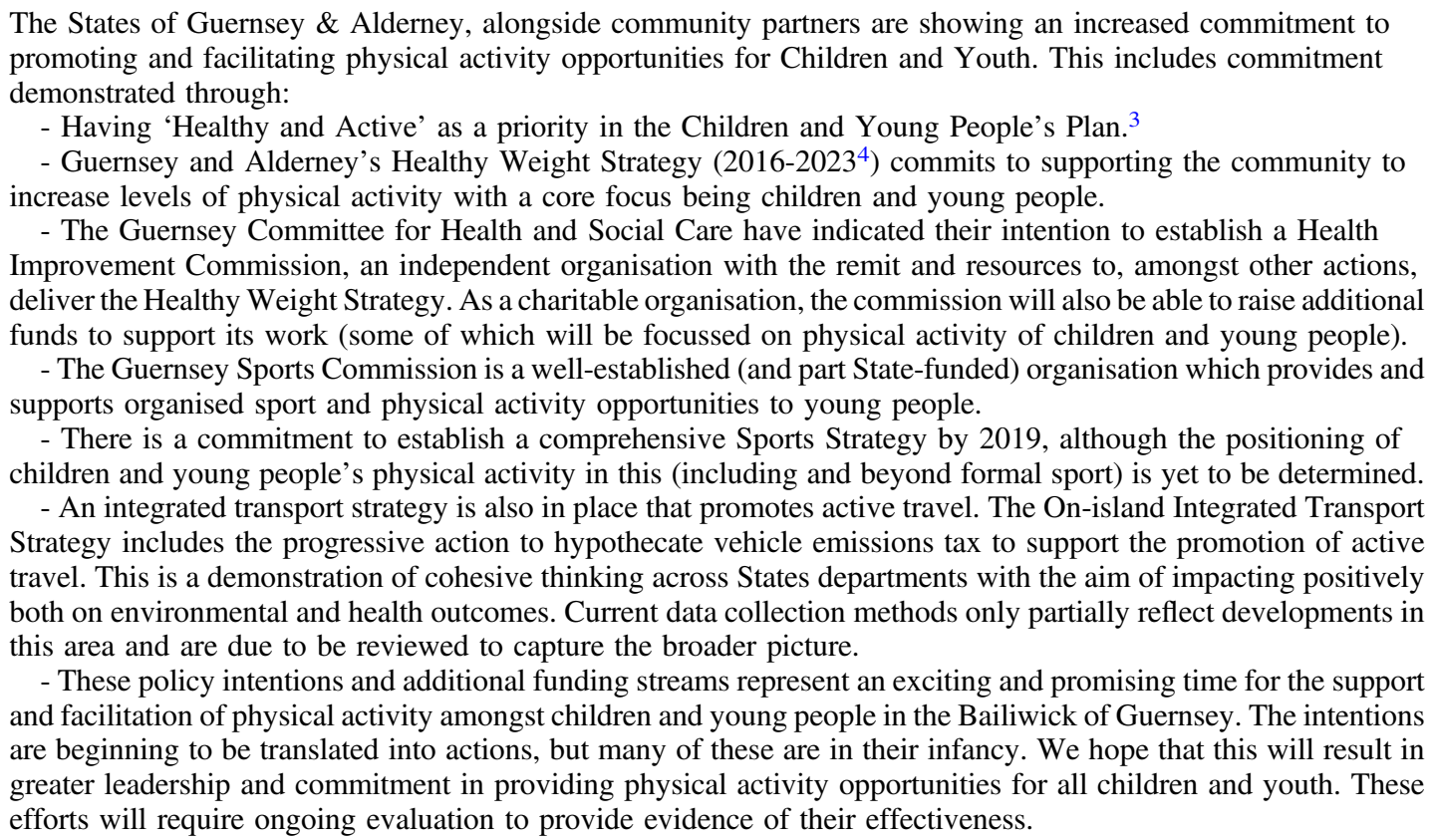 \\
\hline
\end{tabular}

\section{References}

1. Wilkie H, Standage M, Sherar L, et al. Then \& Now: The 2016 active health kids england report card of physical activity for children and youth. 2016. https://www.activehealthykids.org/wp-content/uploads/ 2016/11/england-report-card-short-form-2016.pdf.
2. States of Guernsey. Guernsey young people's survey 2016/2017. 2016. https://www.gov.gg/youngpeoplessurvey.

3. States of Guernsey. Children and young people's plan 2016-2022. 2016. https://www.gov.gg/cypp.

4. States of Guernsey. Guernsey healthy weight strategy. 2016. https:// gov.gg/article/120426/Healthy-Weight-Strategy. 